\title{
The Integration of Cultural Industry and Its Management Innovation
}

\author{
Yiwen $\mathrm{Lu}^{1, \mathrm{a}}$ \\ ${ }^{1}$ Oxbridg College, Kunming University of Science and Technology, Kunming City, Yunnan Province, \\ 650106, China
}

Keywords: cultural industry; cross-border integration; development situation; management innovation

Abstract. Since the 12th Five-Year Plan, under the proposal and drive of the Communist Party of China(CPC) and the government of China(GOC), the development of cultural industries' cross-border integration has been developing. However, the lag of the mechanism of cultural management system caused the cross-border integration of cultural industries of China. Based on my experiences of work and learning, the paper analyzed the important meaning as well as the current situation of cultural industries' cross-border integration and on this basis, and finally put forward management innovation of it. This paper considers that to improve the developments of cultural industries especially the cultural innovation industries' integration, to continue the innovative thinking, search motivations of integration, promote quality of integration as well as grasp the nature of integration.

\section{Introduction}

The eighteenth CPC national congress report clearly pointed out that to promote the integration of culture and technology, develop new cultural commercial activities, improve the levels of cultural industry large-scale, intensification and professionalization. Premier Li Keqiang also emphasized in annual government work report that promote the integration development of cultural originality and design services as well as related industries. Under the proposal and drive of CPC and GOC, since the 12th Five-Year Plan, the cross-border integration of cultural industries have been in accelerated development and even gotten somewhere what makes the situation of "small and weak" of Chinese cultural industries has a certain extent change. However, what we also see at the same time is the trouble is still tough if we want to improve the cross-border integration of cultural industries healthy and smooth and the lag of the system of management mechanism is the main source of obstacles what made the development of Chinese cross-border integration of cultural industries "barely" and "immature". How to innovate the system of cultural management mechanism and develop new patterns of cross-border integration of cultural industry is an important topic that must be answered of promoting the innovation of cultural system.

\section{The significance and the current situation of the development of cultural industry integration}

The significance of the development of cultural industry integration. It benefits to improve the core competitiveness of the cultural industry, promote the cultural industry to achieve leapfrog development. The development of cultural industry is related to tourism, sports, information, logistics, construction and other related industries. The development of cultural and related industries integration will make cultural industries resources configuration effectively in a more large scale and build up a more perfect industry sources supply system; promote cultural industries into the road of large-scale and form economic of scope; make the development of cultural industries categories more complete, more rich, and provide a broader platform for the development of cultural industries, so as to promote cultural industries to develop faster and better.

It also benefits to boost related industries' transformation and upgrade, and promote ecological optimization of economic development. As an intensive knowledge industry, cultural industry has strong permeability and the cross-border integration of cultural industry can make some advanced 
cultural symbols' value, idea, originality and other new elements integrate into the developments of related industries; accelerating the extend to the both ends of industrial chains of related industries as well as the high-end rising of industrial chains, rising the additional values and bestowing new industrial forms, business models and power mechanisms of development of related industries, consequently promote the transformations of development ways of related industries. All of these will make the existing industrial structures better powerfully, adjust industrial elements' pattern and promote the zoology optimizing of Chinese economical development.

The current situation of the development of cultural industry integration. From 2013, Chinese cross-border integration of cultural industries has been showing a strong momentum and emerging a lot of events of merger of cultural cross-border, such as Huayi Brothers invested billion yuan to "marriage" with Yinhan technology, Tianzhou Culture invested billion to purchase Beijing magical era network limited company and Light Media invested billion purchase Xinli Media limited liability company, etc. The domain of mergers contains game, media, cinema, advertising, video, film and television production and mobile Internet application, etc, and it shows the development trend of integration to the depth of the industry. The powerful force of cross-border integration strongly promote the development of Chinese cultural industry. But on the whole, the development of cross-border integration of Chinese cultural industry is still in the initial stage and compared with western developed countries is "immature".

Above all, from the quantitative perspective, Chinese is still not form the cross-border aircraft carriers such as SONY, Time Warner and Disney. The scale of cross-border reform is still relatively small. As the last century in the United States, the Disney purchased the metropolitan American Broadcasting Company with 19 billion dollar, American Telephone and Telegraph Company purchased American Distance Communication Company with 48 billion dollar and Viacom purchased CBS with 37 billion dollar. By 1999, three famous broadcasting companies in America have all been merged. In 2001, 160 billion of the merge of Time Warner and On-Line Company in America was approved and set the highest record in the history of the restructure of the global cultural industries.

Then, from the qualitative perspective, some of the current domestic cultural industries overcome the foundation and need of internal development during cross-border integration, blindly pursue the large and entire of forms and even go into some industries with little related and new industries. Finally caught into the dilemma of management as cross-order integration beyond the scope of its operation ability. In addition, there are little regional and international successful cases of cross-border integration. Because of Chinese integration of cultural industry adopts "government led, enterprise self-propelled". Therefore, to some extent, these problems and deficiencies show the flaws of Chinese cultural management system mechanism which demands prompt solutions.

\section{The management innovation of cultural industry cross-border integration}

Searching the power of commercial activities merger. First of all, the value of aesthetic is rising. In the modern consumer market, as people's need of spiritual culture is increasingly plentiful, the products which take aesthetic function seriously can bring visual and psychological feelings of aesthetic and joviality, such as the elegant design of Nike shoes, the packaging of old red tea and the appearance of Coca-Cola's glass bottles, etc. Based on the guarantee of products' function needs, industries always hope greater profits by integrating originality and design.

Secondly, the originality is realized. As the cultural originality and design service have the characteristics of intangible assets, and only with the help of related industries, can them enter into fields of circulation and consumption and make their relevant meanings in reality. For example, both the design ideas of Apple Inc is full of human culture and its splendid industrial design are famous in all over the world. But left the support of related service providers and manufacturers in the content, technology, craft, equipment, material and other aspects, it will not realize the magnificent feat of "change the world". Originality is not for itself, but the needs of the value's guarantee. The process of realizing the needs, which is also a process of continuous industries' integration. 
Thirdly, the brands are building. At the time of cultural originality and design service can play an important role in increasing the cultural connotation of the products and improve the brand value functions, the industries will increase the investment of related creativity, design, advertising, software and so on.

Taken together, both aesthetic value, originality realizing, or brand building, the core lies in increasing the added value. The high intellectual and high value-added of cultural originality and design service is one of the main driving forces to promote the integration of industries.

Rising the quality of industrial integration. The one is to accelerate the ideas of transformation, promote the transformation of industrial integration to the elements of fusion. The characteristic of cultural industry that look down on asset but think highly of creativity, make it has natural attribute of industrial integration. But the quality of the integration depends on the flow of factors is reasonable or not as well as resource allocation is optimized or not. "Agglomeration of factors is not agglomerate the external factors together simply, or to have or possess, but let the various elements come into play together, carry through the cooperation of key elements, and introduce innovative elements, and then, make the rising of elements' value in reality. Its essence is an integrated process of innovation". Compared with the traditional industrial integration ideas, to grasp originality, information, capital, technology and talent, etc, can make the quality of industrial integration better.

The two is to enhance efforts to realize the propulsion from surface integration to deep integration. China is recognized as a cultural nation, but has not yet become recognized as a "powerful cultural country", the fundamental reason is that a large number of outstanding cultural resources is still to be developed or superficial developed.The depth of integration between the cultural industry and related industries is not enough. For example, the scale of domestic film market is huge, but the consumption of the film content is almost "one-off", and the cost recovery over relies on the box office; but the Hollywood thinks highly of the depth of excavation and repeated development, and built the bridge between the film and publishing, tourism, manufacturing, retail and other industries, but also output American culture and values. The depth of fusion often depends on the height of the work, therefore, continue to strengthen the original and cultivate a number of cultural products that the market recognized is still the only way to achieve the deep integration.

The three is to continually broaden the ideas of realizing the crossing of mixed from two factors to many factors. The cross-border integration can not be simply interpreted as the additive operation, but should be through the combination algorithm to realize the adjustment and optimization of internal structure, organizational form the and the form of product. At present, the development of technology and economy change rapidly and the update cycle is greatly shortened as well as the survival of the fittest speed. How to carry out multiple angle, multiple pattern, multiple form and multiple channels of a kind of cultural originality or single mode, and form the formation of multiple as well as strong vitality integration industry are the directions of continually effort of development of future cultural industry.

Grasp the essence of the industrial integration. First of all, it is the transformation of industry. Transformation means limited resource reallocation between industries can promote technology, capital, labor and other factors of production shift from declining industries to new industries, such as the transformation of traditional agriculture into tourism resources to tourism agriculture, the digital transformation of traditional publishing to digital publishing technology and the transformation of the traditional retail to e-commerce with the help of software service,etc. When the traditional extensive management pattern does not adapt to the new demands of economic development, to achieve the transformation is benefits to reverse the decline of traditional industries and make them have the rebirth opportunities in the new round of business circles of both industrial fission and cross-border integration.

Secondly, it is the industrial innovation. The process of integration is also a process of innovation, the reason is that the process of inter industries' cross penetration and frequent flow of industrial elements which can give rise to a large number of new industrial forms. Especially the extensive application of modern science and technology in the field of culture which formed some emerging 
cultural formats, such as mobile Internet media, digital entertainment, digital digital publishing and education, etc.

\section{Summary}

As the cultural industry entered a new period of development, the trends of industry fission and cross-border integration are obvious, newly-developing cultural industries emerge in endlessly, the cross integration deepen continually and the cultural carrier is increasingly powerful. The incentives include the stimulation of revolution of science and technology, the innovation of business model, the pursuit of the core competitiveness of enterprises, changes in the social and psychological consumption structure and industrial agglomeration, etc. The management innovation of the cross-border integration of cultural industry should start with the following aspects: the one is to search the power of industrial integration; the two is to enhance the industrial integration quality; the three is to grasp the essence of industrial integration.

\section{References}

[1] Wang Zibo. The path thinking of cross-border integration development of cultural industries in minority areas [J]. Guizhou ethnic studies, 2015, (10): 143-146.

[2] Li Fengliang, Zong Zupan. Cross-border integration: the road of innovation development of cultural industry [J]. Tianjin Social Sciences, 2015, (): 49-53.

[3] Li Fengliang, Zong Zupan. Research on the cross-border integration of cultural industry in the context of science and technology [J]. academic research, 2015, (): 137-141+160.

[4] Chen Shengxian. Strategic thinking on the integration of Wushu culture industry [J]. Chinese Wushu (Research), 2015, (01): 61-65.

[5] Liu Yuzhu. Cross-border integration of cultural industry [J]. China broadcasting, 2014, (06): 93-94.

[6] Miao Juan. Cultural cross-border integration boosts industrial upgrading [J]. South TV, 2014, (01): 18-20.

[7] Chen Zhilei. The meaning of cultural industries' cross-border integration and the significance of the main path [J]. Association Forum (second half), 2013 (04): 190-191. 